\title{
Reestruturação organizacional: os principais desafios para 0 Ministério Público do Rio Grande do Norte
}

\author{
Jean Marcel Cunto Lima \\ Universidade Federal do Rio Grande do Norte / Mestrado em administração \\ Ministério Público do Estado do Rio Grande do Norte \\ Natal / RN - Brasil \\ Juliana Perez Ruggiro Jacobini \\ Universidade Federal do Rio Grande do Norte / Mestre em administração \\ Natal / RN - Brasil \\ Maria Arlete Duarte de Araújo \\ Universidade Federal do Rio Grande do Norte / Programa de Pós-Graduação em \\ Administração \\ Natal / RN - Brasil
}

\begin{abstract}
Este artigo visa avaliar o processo de reestruturação organizacional do Ministério Público do Estado do Rio Grande do Norte (MPRN) ocorrida no ano de 2010, verificando os impactos administrativos decorrentes do processo de mudança e implantação da nova estrutura organizacional. Os dados foram obtidos através de documentos, relatórios e juntamente aos integrantes da administração superior e cargos de direção no MPRN. Os dados demonstram que o processo de modernização administrativa teve boa aceitação entre os entrevistados e que melhorou o desempenho e a produtividade de suas unidades. A pesquisa conclui que houve avanço no desempenho institucional, mas que se faz necessária, para consolidação das novas rotinas estabelecidas, a melhoria da comunicação entre as unidades administrativas e entre demandantes e demandados a fim de assegurar a efetividade do projeto.
\end{abstract}

Palavras-chave: organizações; administração pública; estrutura organizacional.

Reestructuración organizacional: principales desafíos para el Ministerio Público de Rio Grande do Norte

Este artículo tiene como objetivo evaluar la reestructuración organizativa del Ministerio Público de Río Grande do Norte (MPRN) se produjo en 2010, comprobando los efectos administrativos del proceso de cambio y la implementación de la nueva estructura organizativa. Los datos fueron obtenidos a través

DOI: http://dx.doi.org/10.1590/0034-7612134712

Artigo recebido em 11 maio 2014 e aceito em 28 maio 2015. 
de documentos, informes y a los miembros de la Alta Dirección y posiciones ejecutivas en MPRN. Los datos demuestran que el proceso de modernización administrativa fue bien aceptado entre los encuestados y que mejora el rendimiento y la productividad de sus unidades. La investigación concluye que no ha habido avances en el desempeño institucional, pero que es necesario consolidar las nuevas rutinas establecidas, mejorar la comunicación entre las unidades administrativas y entre demandantes y demandados a fin de garantizar la eficacia del proyecto.

Palabras clave: organizaciones; administración pública; estructura organizacional.

Organizational restructuring: major challenges for Public Ministry of Rio Grande do Norte This article aims to assess the organizational restructuring of the Public Ministry of Rio Grande do Norte (MPRN) occurred in 2010, checking the administrative impacts of the change process and implementation of the new organizational structure. Data were obtained through documents, reports, and with the members of the Senior Management and executive positions in MPRN. The data demonstrate that the administrative modernization process was well accepted among the respondents and that improved the performance and productivity of its units. The research concludes that there has been progress in institutional performance, but that it is necessary to consolidate the new routines established the improvement of communication between administrative units and between plaintiffs and defendants in order to ensure the effectiveness of the project.

KEYWORDS: organizations; public administration; organizational structure.

\section{Introdução}

As transformações sofridas pela administração pública vêm sendo amplamente debatidas. A herança patrimonialista e as disfunções da burocracia permeiam as discussões em torno de um novo modelo de gestão pública voltado para uma atuação do Estado eficiente, eficaz e efetiva ante as crescentes demandas sociais.

A partir dos anos 1980, cristaliza-se um movimento de reforma administrativa iniciado na Inglaterra sob o comando da ministra Margareth Tatcher e posteriormente nos Estados Unidos no governo de Ronald Regan.

Os elementos apontados como ativadores dessas ondas de "modernização" foram a crise fiscal do Estado (Aucoin, 1990; Hood, 1995; Pollitt e Bouckaert, 2002), a crescente competição territorial pelos investimentos privados e mão de obra qualificada (Subirats e Quintana, 2005), a disponibilidade de novos conhecimentos organizacionais e tecnologia, a ascensão de valores pluralistas e neoliberais (Kooiman, 1993; Rhodes, 1997) e a crescente complexidade, dinâmica e diversidade das sociedades contemporâneas (Kooiman, 1993).

Nesse cenário, as mudanças propostas focalizaram em um primeiro momento a redução do tamanho do Estado com as privatizações e terceirizações e, em um segundo momento, as reformas foram direcionadas para a melhoria da capacidade institucional de gestão. Tratavase de introduzir um conjunto de reformas inspiradas na iniciativa privada e que privilegiavam temas como avaliação de desempenho, contratualização, contratos de gestão, produtividade e eficiência. 
No Brasil, esse movimento teve início com a Reforma Gerencial do Estado Brasileiro, durante o primeiro governo Fernando Henrique Cardoso, com a elaboração do Plano Diretor de Reforma do Aparelho do Estado, em 1995. O objetivo consistia em superar as disfunções da gestão pública burocrática para tornar o Estado mais eficiente (Andriolo, 2006; Bresser-Pereira, 2001).

De 1995 até os dias atuais, muitas ações têm sido empreendidas por diversas organizações públicas no sentido de melhorar a gestão, promover accountability, estabelecer canais de comunicação com o cidadão, criar mecanismos de transparência e buscar novos arranjos organizacionais para a execução das políticas públicas.

A gestão passa assim a ser cada vez mais valorizada para o atendimento das múltiplas demandas do cidadão. Trata-se de ampliar a capacidade institucional de gestão para melhorar a capacidade estatal. Regras do jogo, relações interinstitucionais, arranjos organizacionais, parcerias, políticas adequadas de pessoal e de alocação de recursos tecnológicos, financeiros e materiais, preocupação com resultados, entre outras exigências próprias da racionalidade instrumental, passam a fazer parte da agenda dos governos.

Nesse cenário, o Ministério Público do Rio Grande do Norte (MPRN), preocupado com as crescentes demandas da sociedade em relação aos serviços prestados pela Instituição, marcados ainda pela dificuldade de compatibilização entre demanda e estrutura, implementou um processo de modernização de sua estrutura organizacional com o objetivo de melhorar a eficiência administrativa e a governança interna e, por conseguinte, a capacidade de atendimento à população.

Decorridos aproximadamente três anos da mudança, é pertinente verificar se a estrutura implementada contribuiu para a melhoria do desempenho institucional e quais foram os impactos administrativos produzidos. Esses temas constituem o objetivo deste artigo.

A pesquisa foi realizada com dados secundários por meio de pesquisa de referências bibliográficas e documentais - relatórios, projetos e atas de reuniões do MPRN. Realizou-se também uma pesquisa de campo com diretores e integrantes da administração superior do MPRN, no total de oito pessoas, que compõem o corpo estratégico da Instituição. A coleta foi realizada no período de 15 a 27 de julho de 2011 a partir da aplicação de um questionário.

Este artigo está estruturado em seis seções, incluindo esta introdução. A segunda seção trata da natureza das organizações públicas explorando aspectos da estrutura e mudanças no setor público; a terceira contextualiza o Ministério Público brasileiro e apresenta a experiência de reestruturação do MPRN; a quarta discute o percurso metodológico; a quinta analisa as melhorias do desempenho institucional e os impactos produzidos com a reestruturação organizacional no MPRN a partir da ótica dos gestores em cargos estratégicos; e, finalmente, a sexta seção tece considerações finais sobre o processo de mudança.

\section{Organizações públicas: particularidades, estrutura e mudanças}

As organizações públicas possuem particularidades decorrentes de sua própria essência: atuam em nome do povo — em nome da sociedade — e suas ações têm consequências para os 
indivíduos e os grupos sociais. Todos que participam da administração pública tomam decisões com base em leis e normas. Segundo Dussault (1992:13),

as organizações de serviços públicos dependem em maior grau do que as demais do ambiente sociopolítico: seu quadro de funcionamento é regulado externamente à organização. As organizações públicas podem ter autonomia na direção dos seus negócios, mas, inicialmente, seu mandato vem do governo, seus objetivos são fixados por uma autoridade externa.

As organizações públicas possuem natureza sui generis, pois sua finalidade é atender ao interesse público, estando inserida em um ambiente político e técnico, possuindo tanto prerrogativas como restrições impostas por lei que impactam sobremaneira a constituição de sua estrutura organizacional e particularizam consideravelmente seu funcionamento em comparação com as entidades privadas.

Corroborando esse entendimento, Matus (1993) reforça que não existe dissociação entre o político e o técnico na administração pública, e que o mais correto é pensar as questões na perspectiva do processamento técnico-político no âmbito das organizações da administração pública. Misoczky, Vieira e Leão (1999) também compartilham desse pensamento ao tentarem articular os diversos parâmetros presentes na administração pública às dimensões políticas e técnicas, conforme revela o quadro 1.

Quadro 1

Dimensões políticas e técnicas na administração pública

\begin{tabular}{|cll|}
\hline Parâmetro & \multicolumn{1}{c|}{ Dimensão política } & \multicolumn{1}{c|}{ Dimensão técnica } \\
\hline Esfera de ação & A sociedade como um todo & $\begin{array}{l}\text { Dar racionalidade formal ao processo de } \\
\text { decisões sociais }\end{array}$ \\
Valores & Uma verdade pragmática & Uma verdade científica \\
Critério de eficácia & Poder & Alternativa mais econômica \\
Instrumento de ação & Decisão política & Argumentação técnica \\
Tipo de racionalidade & $\begin{array}{l}\text { Material - capacidade de alterar ou não as } \\
\text { relações de poder }\end{array}$ & $\begin{array}{l}\text { Formal - cadeia de objetivos e meios para } \\
\text { que sejam atingidos }\end{array}$ \\
\hline
\end{tabular}

Fonte: Misoczky, Vieira e Leão (1999).

Isto significa que a administração pública se orienta por vetores normativos que incluem um conjunto de orientações, crenças e valores que influenciam as decisões políticas e técnicas, tanto no âmbito interno como externo, e que o resultado da ação combinada das diferentes dimensões (política e técnica) modifica os próprios parâmetros de atuação da administração pública. O quadro 1 evidencia como os parâmetros podem ser vistos a partir de óticas distintas, mas complementares e, ao mesmo tempo, revela que as dimensões políticas e técnicas são explicadas a partir dos parâmetros ou vetores valorativos e normativos que expressam a configuração que assume a administração pública. 
Essa concepção nem sempre foi dominante, pois durante algum tempo a política e a administração eram coisas distintas. Como afirmam Harmon e Mayer (1999:50),

durante su primer medio siglo como consciente campo de estudio (aproximadamente desde fines del decenio de 1880 hasta mediados del de 1940), la ortodoxia de la administración pública estuvo firmemente fincada en la severa advertencia de Woodrow Wilson de que la administración política debía mantenerse separada de la política. La idea de que administración y política son actividades lógica y normalmente separadas sirvió como fundamento a la temprana ortodoxia de la administración pública. Esta separación — eso se creía — permitiría la formulación de principios científicos generalizados de administración que no serían contaminados por la vulgar intrusión de la política.

A compreensão de que política e administração deviam ser separadas orientou o pensamento de que os problemas administrativos são de índole técnica e, portanto, suscetíveis apenas de análise lógica ou empírica. Como afirma Behn em Abrucio e Loureiro (2004:78), "por mais de cem anos, estivemos mantendo a ficção de que funcionários públicos (burocratas ou técnicos) não fazem política".

Na mesma linha de raciocínio, Rua contesta a ideia de que administração e política são esferas distintas e levanta um conjunto de indagações sobre o que seria a neutralidade burocrática apregoada como garantia de que os assuntos do Estado seriam conduzidos fora do jogo de influências políticas. Afirma ela que

estudos recentes têm mostrado que, diversamente do que pretendia a separação analítica entre política e administração, fica claro que os agentes administrativos não são neutros, mas sim dotados de interesses próprios, que tentam maximizar. Agem como atores políticos, mostrando-se capazes de mobilizar recursos políticos, como informação e apoio de grupos de interesse da sociedade. Além disso, possuem capacidade para desenvolver concepções próprias sobre as políticas governamentais e sobre o seu próprio papel no jogo político, independentemente de considerações de natureza estritamente técnica. (Rua, 1997:142)

Em decorrência, pergunta: a neutralidade burocrática seria um valor absoluto ou implicaria consequências que imporiam a discussão acerca da sua desejabilidade ou conveniência?

Na mesma linha de raciocínio, Bresser-Pereira (1998) afirma que, sendo a sociedade um campo de conflito, cooperação e incerteza, na qual os cidadãos defendem seus interesses e afirmam suas posições ideológicas, a crença em uma racionalidade absoluta que a burocracia deve garantir na condução dos assuntos públicos é insuficiente para lidar com o atendimento pelo Estado do interesse coletivo na produção de bens públicos ou "quase públicos".

Assim, os modelos de administração pública no Brasil vão estar estreitamente vinculados à forma como os diversos interesses operam na arena pública e configuram características definidoras do formato que o Estado vai assumir, seja patrimonialista, burocrático ou gerencial. 
Uma breve incursão pelo assunto vai revelar que o Estado patrimonialista do início do século XX era um Estado dominado pelas oligarquias rurais e marcado pelas práticas administrativas permeadas por paternalismo, nepotismo e corrupção e pela confusão entre o público e privado. O poder político estava concentrado em um grupo dominante que deriva seu poder e renda do próprio Estado. Como afirma Bresser-Pereira (2001:4),

o Estado brasileiro de 1900 é ainda um Estado oligárquico em que uma pequena elite de senhores de terra e de políticos patrimonialistas dominavam amplamente o país. (...) O Estado arrecada impostos das classes, particularmente da burguesia mercantil, que são usados para sustentar o estamento dominante e o grande corpo de funcionários de nível médio a ele ligados por laços de toda ordem.

Em um segundo momento, ainda no século XX, vivenciou-se a idealização e implantação de um modelo burocrático de organização da administração pública a partir da Revolução de 30. Nunes (1997), examinando a construção do insulamento burocrático e do corporativismo e nacionalização do clientelismo no Brasil, afirma que

Durante os 15 anos do primeiro governo Vargas (1930-45), três novas gramáticas para as relações entre Estado e sociedade foram experimentadas pelas agências e regulamentações recémcriadas: implementou-se a legislação corporativista, e foram criadas instituições corporativistas; ensaiou-se o insulamento burocrático, através da criação de novas agências e empresas estatais; buscou-se instaurar o universalismo de procedimentos, principalmente através de tentativas de reforma do serviço público e da implantação de um sistema de mérito. (Nunes, 1997:47)

Entre as medidas adotadas constavam a criação do Departamento Administrativo do Serviço Público (Dasp), cuja missão fundamental era formular e executar a nova forma de pensar e organizar a administração pública, com destaque para o ingresso no serviço público por concurso, administração orçamentária, padronização das atividades e racionalização dos métodos.

Em 1967, um esforço de natureza gerencial foi feito através da desconcentração para administração pública indireta, com o Decreto-Lei no 200, garantindo-se uma ampliação da autonomia para as autarquias, fundações e empresas estatais e normas mais flexíveis para a condução das atividades públicas. No entanto, a reforma não logrou êxito, pois não conseguiu mudar os aspectos fisiológicos que marcavam a administração e nem fortalecer uma burocracia mais permeável às demandas do cidadão.

As ideias da reforma gerencial são retomadas a partir de 1995, com a criação do Ministério da Administração e Reforma do Estado (Mare), em sintonia com diversos movimentos de reforma em muitos países. A modernização ou o aumento da eficiência da administração pública

será o resultado a médio prazo de um complexo projeto de reforma, através do qual se buscará a um só tempo fortalecer a administração pública direta ou o "núcleo estratégico do Estado" e 
descentralizar a administração pública através da implantação de "agências autônomas" e de "organizações sociais" controladas por contratos de gestão. Nestes termos, a reforma proposta não pode ser classificada como centralizadora, como foi a de 1936, ou descentralizadora, como pretendeu ser a de 1967. (Bresser-Pereira, 1998:24)

Nos dias atuais, percebe-se que as iniciativas em torno da modernização da gestão pública têm conquistado espaço de destaque nas discussões sobre melhoria da gestão pública e são constantes as iniciativas inovadoras encaminhadas pelos estados e municípios, tanto na melhoria da eficiência administrativa, quanto na forma de prestação de serviços aos cidadãos.

O movimento de criação de novas capacidades de gestão da administração pública exige melhorias dos fluxos de trabalhos, dos processos decisórios, das comunicações e, por conseguinte, uma estrutura organizacional adequada que resulte em uma mudança substantiva da capacidade institucional de gestão.

Nesse sentido, a estrutura organizacional de uma instituição é entendida por muitos autores como a ordenação e o agrupamento de atividades e recursos para o alcance dos objetivos (Oliveira, 2002; Cury, 2006).

Seiffert e Costa (2007:28) entendem estrutura organizacional como "a distribuição de pessoas entre posições sociais que influenciam os relacionamentos de papéis desempenhados por elas". Ainda segundo os autores, essa distribuição possui duas implicações: a divisão de trabalho (distribuição de tarefas entre as pessoas) e a hierarquia (distribuição das pessoas em posições), de modo que o resultado dessa estrutura visa gerar produtos organizacionais e atingir metas; minimizar as variações individuais sobre a organização e estabelecer o contexto na qual o poder é exercido (Seiffert e Costa, 2007). Vasconcelos e Hemsley (2003) acrescentam a variável comunicação entre as funções precípuas da estrutura organizacional.

A estrutura de uma organização pode ser definida como resultado de um processo por meio do qual a autoridade é distribuída, as atividades desde os níveis mais baixos até a alta administração são especificadas e um sistema de comunicação é delineado permitindo que as pessoas realizem as atividades e exerçam a autoridade que lhes compete para o atingimento dos objetivos organizacionais. Isto implica dizer que a estrutura organizacional, ao dispor as atividades a serem realizadas e definir a responsabilidade dos atores para sua realização, estabelece imediatamente uma relação hierárquica e, por conseguinte, de poder. Ao mesmo tempo, para que as atividades ocorram, define uma rede de comunicações que por sua vez permite um fluxo de ordens e significados que são compartilhados por todos os atores. Assim, a estrutura é a um só tempo reveladora das relações econômicas, ideológicas e simbólicas da organização. Compreender a complexidade da estrutura organizacional é assim criar condições para que a mudança organizacional possa acontecer.

De uma perspectiva situacional, Herzog (1991) diz que existem três situações capazes de provocar ou catalisar uma mudança organizacional com implicações na estrutura organizacional: crises ou problemas, novas oportunidades, e novas diretrizes internas e externas.

Seguindo a mesma linha, Pettigrew (1987) afirma que dentro do processo de mudança organizacional estão inseridas as ações, reações e interações organizacionais, que contem- 
plam a temporalidade contínua entre o passado e futuro. Ainda de acordo com o autor, tal fato caracteriza um processo de adequação mútuo entre a organização e o ambiente no qual está inserida.

No que concerne às particularidades da administração pública, as organizações do setor público não podem continuar ilesas à necessidade de reestruturação estratégica e de adoção de novas técnicas de gestão necessárias à sua capacitação ao manejo das complexas demandas organizacionais e ambientais (Kliksberg, 1992). As organizações públicas também devem preocupar-se com o aumento da sua eficiência, o que implica mudanças organizacionais que possibilitem agilidade e diminuição da complexidade burocrática na implementação de ações estratégicas (Xavier e Dias, 2002). Em resposta às necessidades de mudança, a Reforma Administrativa do Estado, visando transformar a administração pública burocrática em gerencial, é tema de debate de muitos estudiosos.

Aprofundando a discussão das perspectivas e limitações das mudanças e reformas no Brasil, Souza (1994) afirma que as reformas administrativas no setor público no Brasil têm tido outra característica comum: os comportamentos humanos não são levados em consideração no planejamento da mudança. Segundo esse autor, há "a crença de que, uma vez assinados os documentos formais que enfatizam a mudança, ela, como num passe de mágica, ocorrerá".

Sob uma ótica instrumental, Ferlie e colaboradores (1999) propuseram seis indicadores com o intuito de avaliar o processo de mudança organizacional no setor público em seus vários níveis:

\ Extensão da mudança múltipla, inter-relacionada, no sistema como um todo;

v Criação de novas formas organizacionais no setor público;

v Desenvolvimento de mudanças em cascata que tenham efeito no sistema como um todo até o nível de unidade;

\ Reconfiguração das relações de poder;

V Introdução de mudanças nos serviços prestados e no modo de prestá-los;

• Criação de uma cultura, ideologia e significados organizacionais novos.

Numa visão sistêmica dos processos de mudanças organizacionais da administração pública, verifica-se que são inúmeras variáveis e atores envolvidos na condução desse processo: novos serviços, alterações nas políticas públicas, novas coalizões de poder, novas demandas por parte dos cidadãos. Diante da insatisfação crescente no que se refere à qualidade dos serviços públicos, existe uma pressão da sociedade pela melhoria dos serviços públicos, o que exige, por conseguinte, mudanças nas organizações públicas.

Importante destacar que as mudanças organizacionais na administração pública muitas vezes são lentas, pois exigem criação de estruturas e cargos, que para serem concretizados 
estão sujeitos a um processo legislativo, além dos condicionantes políticos, orçamentários e financeiros do setor público. É comum que esse processo de mudança esteja por vezes aquém das demandas da sociedade.

Para que um processo de mudança organizacional ocorra faz-se necessário que haja um intenso processo de mobilização dos atores que leve ao comprometimento dos mesmos, pois sem que haja uma avaliação positiva da mudança que se deseja implementar é provável que haja um aumento expressivo dos níveis de resistência no âmbito interno e às vezes externo da organização com implicações de toda ordem envolvidas.

No Brasil, o velho e o novo impactam o processo de mudança, na medida em que as forças de permanência e de avanço atuam fortemente. Como ainda não houve mudança radical na cultura do setor público, o passado se impõe ao presente sob várias formas, condicionando-o. O patrimonialismo e a burocracia são os maiores complicadores do processo de modernização, levando a centralização, autoritarismo, distância do serviço público à população e ineficiência (Brasil, 1995).

Por outro lado, percebe-se que as mudanças organizacionais na administração pública se têm acentuado em decorrência de um processo intenso observado nos últimos anos, de uso de práticas provenientes principalmente do setor privado, tal qual o uso da tecnologia da informação (governo eletrônico), utilização de metas e indicadores de desempenho e práticas gerenciais com foco na qualidade do serviço prestado.

No que se refere à transparência na administração pública, a pressão da sociedade, o fortalecimento da democracia e dos órgãos de controle têm impulsionado o setor público a prestar contas das suas atividades à sociedade, fomentando a responsabilização dos gestores e uma cidadania mais ativa.

Ademais, o planejamento orçamentário, a otimização das compras governamentais e a utilização de práticas de gestão e melhoria dos processos da área pública têm permitido um ganho na qualidade da ação pública, que por consequência exige uma administração pública mais flexível, com foco no cidadão e capaz de moldar-se às necessidades do cidadão e da sociedade. Para tanto, a forma pela qual são estruturadas as organizações públicas passa a ser uma questão de suma importância para o cumprimento dos objetivos das organizações públicas. O tópico a seguir trata o processo de reestruturação organizacional do Ministério Público do estado do Rio Grande do Norte.

\section{Processo de reestruturação organizacional do Ministério Público}

\subsection{Ministério Público brasileiro}

A trajetória recente do Ministério Público brasileiro remonta ao ano de 1934 com o Ministério Público no âmbito da Constituição da República. Em seguida, a Constituição de 1937 
traz também algumas citações sem muita expressão. Já a Constituição de 1946 estipula título especial ao Ministério Público, posicionando-o independentemente dos outros Poderes do Estado. Entretanto, somente na Constituição de 1967, o Ministério Público conquista a equivalência aos juízes, o que representou um grande avanço institucional.

A Constituição Federal de 1967 trouxe importantes inovações ao subordinar o Ministério Público ao Poder Judiciário, criando a regulamentação "séria” do concurso de provas e títulos, abolindo os "concursos internos" que davam margem às influências políticas. Ao integrar o Poder Judiciário, o Ministério Público deu importante passo na conquista de autonomia e independência por meio da equiparação com os magistrados. Tais "conquistas" somente seriam consagradas constitucionalmente na Constituição Federal de 1988. A Constituição Federal de 1969 (Ou Emenda Constitucional no 1, de 17 de outubro de 1969) havia retirado as mesmas condições de aposentadoria e vencimentos atribuídos aos juízes (pela supressão do parágrafo único do art. 139) e perda de sua independência, pela subordinação no capítulo do Poder Executivo (Sadek, 2010).

O marco histórico para o Ministério Público no Brasil foi a Constituição de 1988, a qual conferiu ao Órgão autonomia administrativa, financeira e orçamentária, além da desvinculação do Poder Executivo. Ademais, a Carta Magna reservou um capítulo próprio sobre o Ministério Público, representando a maior conquista da Instituição, com novas atribuições, múltiplas intervenções em demandas civis e proteção dos interesses difusos, conforme se extrai do art. 127: “o Ministério Público é Instituição permanente, essencial à função jurisdicional do Estado, incumbindo-lhe a defesa da ordem jurídica, do regime democrático e dos interesses sociais e individuais indisponíveis" (Brasil, 1988).

A Carta Constitucional conferiu ainda ao Ministério Público a titularidade do inquérito civil público e a possibilidade de conduzir Termo de Ajustamento de Conduta (TAC), instrumento jurídico com força de título extrajudicial, por meio do qual o agente causador do dano é levado a assumir responsabilidade pelo mesmo, em acordo firmado com o MP, adotando a partir daí a conduta adequada à superação dos problemas causados e que implicaram prejuízos a direitos transindividuais.

No que se refere ao papel desempenhado no Ministério Público, enquanto Órgão de controle da administração pública, a Lei no 8.428/1992 (Lei da Improbidade Administrativa), que regulamenta o $\$ 4^{\circ}$ do art. 37 da Constituição Federal, conferiu aos membros do Ministério Público a possibilidade de processar qualquer agente público no exercício de mandato, cargo, emprego ou função na administração pública direta, indireta ou fundacional, sem estarem sujeitos à regra de foro especial. Se condenado em ação civil pública por improbidade administrativa, o acusado perde o cargo e tem seus direitos políticos suspensos por oito a 10 anos, além de ser obrigado a ressarcir os cofres públicos.

A Emenda Constitucional no 45, de 30 de dezembro de 2004, cria o Conselho Nacional do Ministério Público (CNMP) com atribuição de controle da atuação administrativa e financeira do Ministério Público e do cumprimento dos deveres funcionais de seus membros. $\mathrm{O}$ 
CNMP foi instalado em junho de 2005 com a missão de imprimir uma visão nacional à instituição e coordenar esforços no cumprimento das funções ministeriais voltadas para a consecução dos objetivos fundamentais da República.

Já no ano de 2013, a derrubada do Projeto de Emenda Constitucional (PEC 37) que, entre outras medidas, propunha o impedimento de o Ministério Público realizar investigações criminais, que passaria a ser exclusiva da polícia judiciária, foi rejeitada em votação na Câmara dos Deputados.

Nesse cenário, contextualizam-se as iniciativas do Ministério Público do estado do Rio Grande do Norte que levaram à implantação de novas práticas gerenciais e à configuração de uma nova estrutura organizacional. No tópico a seguir será apresentado o escorço histórico do MPRN sob a ótica institucional e administrativa.

\subsection{O Ministério Público do estado do Rio Grande do Norte}

A estrutura orgânica do Ministério Público do estado do Rio Grande do Norte é estabelecida por meio da Lei Complementar Estadual no 141/1996, que define estrutura, competências e atribuições dos Órgãos e unidades da Instituição.

Além da Lei Complementar no 141/1996 (Dispõe sobre a Lei Orgânica e Estatuto do Ministério Público do Estado do Rio Grande do Norte), têm-se as principais normas que regem a estrutura funcional do Ministério Público potiguar, quais sejam, Lei Complementar no 446/2010 (Dispõe sobre a estrutura administrativa do Ministério Público do Estado do Rio Grande do Norte), no 447/2010 na Resolução no 74/2011 — MPRN (Regimento Interno).

Importante contextualizar a trajetória do MPRN a fim de compreender e evolução institucional focalizando o crescimento de pessoal, orçamentário e estrutural. No que se refere a este último ponto, até o ano de 2001, quase a totalidade nas Promotorias de Justiça funcionava de forma precária na estrutura do Poder Judiciário e apenas a sede da Procuradoria-Geral de Justiça estava sediada em um imóvel locado. No entanto, atualmente, somente uma sede do interior do estado funciona nas dependências do Poder Judiciário.

No que tange à ampliação da força de trabalho, o quadro de servidores da Instituição foi criado no ano de 2001, ocasião em que a Instituição era composta por 138 promotores de Justiça, 21 procuradores de Justiça e pouco mais de sete servidores efetivos ou cedidos por outras instituições públicas. Nesse período, o promotor de Justiça, na maioria das situações, atuava sozinho nas comarcas do interior do estado, sem qualquer suporte de pessoal.

A seguir, apresenta-se o gráfico 1 com a evolução recente do quadro de pessoal do MPRN.

O Ministério Público está presente em 65 comarcas em todo o estado do Rio Grande do Norte por meio da atuação de promotores de Justiça de $1^{a}$, $2^{\text {a }}$ e $3^{\text {a }}$ entrância e na capital do estado por meio de promotores e procuradores de Justiça. Adiante, segue a figura 1 contendo o mapa das comarcas do MPRN, subdivididas por entrância e situação das suas sedes. 
Gráfico 1

Evolução do quadro de membros, servidores e estagiários

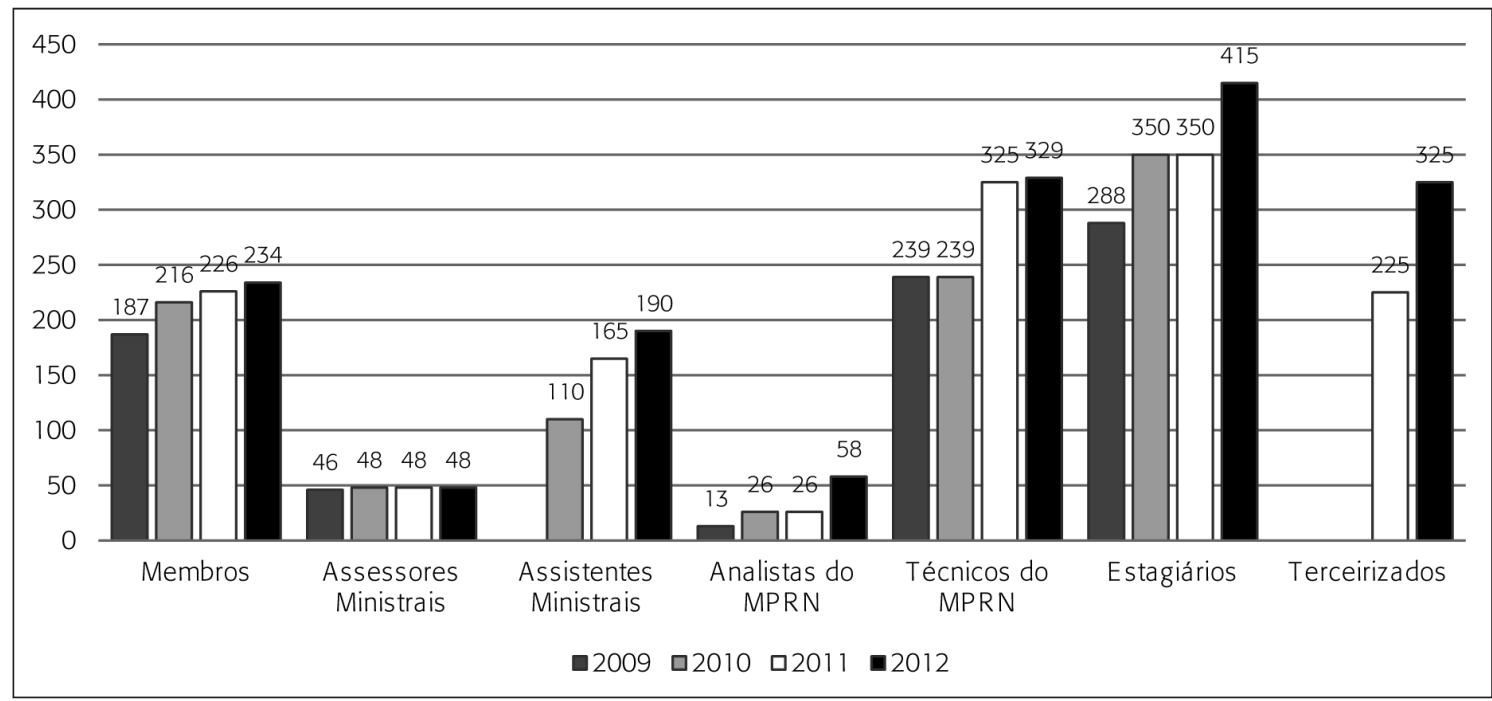

Fonte: Elaborado pelo autor com dados da Diretoria de Gestão de Pessoas do MPRN e Setor de Estágios (2013).

Figura 1

Mapa das comarcas do MPRN

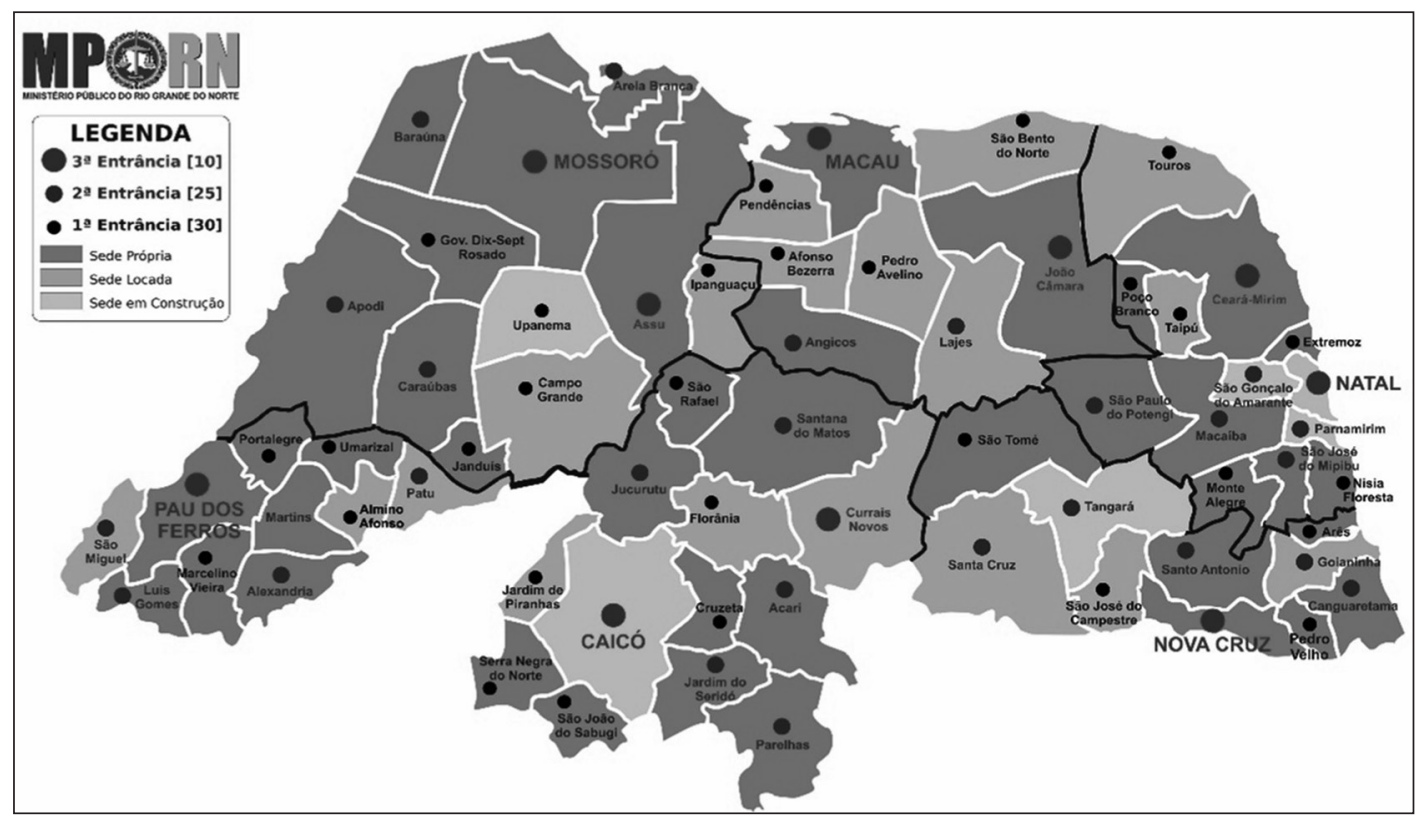

Fonte: <www.mprn.mp.gov.br>. 
O Ministério Público potiguar vive um momento de crescimento intenso, em especial decorrente das atribuições que lhe foram confiadas pela Constituição de 1988. Para melhor demonstrar esse processo de crescimento, apresenta-se a tabela $1 \mathrm{com}$ alguns números sobre a evolução da execução da despesa no período de 2008-13, representando os gastos com pessoal, manutenção e funcionamento e investimentos.

Tabela 1

Evolução da despesa 2008-13

\begin{tabular}{|lrrrrrrr|}
\hline \multicolumn{7}{|c|}{$\begin{array}{c}\text { Comparativo da despesa realizada } \\
\text { Exercícios 2008 a } 2013\end{array}$} \\
\hline Despesa & 2008 & 2009 & 2010 & 2011 & 2012 & 2013 \\
\hline Pessoal & $83.840 .561,04$ & $94.964 .930,33$ & $115.079 .217,77$ & $127.872 .867,62$ & $141.115 .639,15$ & $170.527 .284,30$ \\
Custeio & $6.721 .772,85$ & $8.732 .871,30$ & $14.788 .845,53$ & $24.203 .122,39$ & $36.289 .644,81$ & $42.102 .720,70$ \\
Investimento & $6.086 .247,05$ & $3.334 .800,64$ & $2.823 .562,94$ & $8.808 .945,53$ & $8.900 .022,12$ & $9.056 .913,44$ \\
Total & $96.648 .580,94$ & $107.032 .602,27$ & $132.691,626,24$ & $160.884 .935,54$ & $186.305 .306,08$ & $221.686 .918,44$ \\
Variação (\%) & - & $10,74 \%$ & $23,97 \%$ & $21,25 \%$ & $15,80 \%$ & $18,99 \%$ \\
\hline
\end{tabular}

Fonte: Elaborado pelos autores com os dados do Sistema Orçamentário, Financeiro e Contábil do MPRN.

Faz mister frisar que, muito embora a Procuradoria-Geral de Justiça tenha crescido em todas essas dimensões, a estrutura gerencial do Ministério Público Estadual praticamente manteve-se inalterada nos últimos 10 anos, funcionando por meio de 13 unidades administrativas responsáveis pela gestão da Instituição e atendimento a toda a demanda interna e externa do MPRN e organizada através de áreas burocráticas, voltadas apenas para manutenção da rotina de trabalho (recursos humanos, folha de pagamento, finanças, material e patrimônio e informática).

A necessidade de compatibilizar a estrutura organizacional às demandas decorrentes desse crescimento, assim como a necessidade de ampliar o atendimento à população e otimizar os serviços prestados decorrentes da percepção entre os integrantes do MPRN de ineficiência e baixa produtividade registrados no processo de autoavaliação realizado pela Instituição por meio da ferramenta do Programa Nacional de Gestão Pública e Desburocratização (GesPública), evidenciou a urgência em implementar um processo de mudança organizacional.

O GesPública foi instituído pelo Decreto no 5.378, de 23 de fevereiro de 2005, e é considerado fruto da evolução de diversas iniciativas do governo federal para a promoção da gestão pública de excelência com o intuito de contribuir para a qualidade dos serviços públicos prestados ao cidadão. O programa é orientado ao cidadão e fundamentalmente público, respeitando os princípios constitucionais da impessoalidade, da legalidade, da moralidade, da publicidade e da eficiência. Além disso, está voltado para o alcance de melhores resultados para a sociedade (Palvarini, 2010:1). 


\subsection{0 início do processo de reestruturação do MPRN}

No que tange à autoavaliação realizada pelo MPRN no ano de 2007, alcançaram-se 154,75 em um total de 250 pontos possíveis, conforme a metodologia do GesPública. Ressalte-se que o instrumento de avaliação utilizado foi adequado para organizações que estão na fase inicial de desenvolvimento gerencial, existindo ainda instrumentos de 500 e 1.000 pontos para organizações mais avançadas. Em consonância com os resultados da autoavaliação, o MPRN foi avaliado da seguinte forma: práticas nos primeiros estágios de desenvolvimento e implementação; lacunas significativas na maioria das práticas; e surgimento de alguns resultados decorrentes da aplicação das práticas implementadas com algumas tendências favoráveis.

A autoavaliação e o relatório apresentados pela equipe responsável pelo plano de melhorias apontaram a necessidade de elaboração de um planejamento estratégico, o qual foi realizado pela Instituição no ano de 2008 e que demonstrou um conjunto de deficiências. Entre outras:

$\checkmark$ ineficiência de procedimentos e processos de trabalho;

$\checkmark$ falhas no atendimento das demandas internas oriundas das Promotorias e Procuradorias de Justiça;

$\checkmark$ unidades administrativas sobrecarregadas;

v suporte administrativo inadequado (transporte, tecnologia da informação, segurança, manutenção, limpeza, contratações, entre outros);

$\checkmark$ desvio e segregação de funções;

$\checkmark$ falhas de comunicação e falta de integração entre as unidades.

A compreensão dos problemas, de acordo com o relatório apresentado, levou à decisão por parte da administração do MPRN de que mudanças importantes deveriam ser realizadas para superação dos problemas identificados. Assim, foram definidos objetivos a serem perseguidos pelo MPRN:

$\checkmark$ desenhar uma nova estrutura organizacional que fosse capaz de traduzir o conjunto de atividades, de responsabilidades, de comunicação e de autoridade necessárias ao funcionamento efetivo dos serviços de apoio do MPRN;

v um novo Regimento Interno para as atividades administrativas da Instituição;

- otimização das atribuições, responsabilidades e competências de unidades administrativas;

v criação de estrutura e políticas voltadas para modernização da gestão e qualidade.

Cumpre destacar que, conforme identificado nos documentos pesquisados, o projeto de implantação de uma nova arquitetura organizacional para o MPRN foi concebido com apoio de consultoria externa e contou com a participação de uma comissão composta por servidores, 
designada por ato do procurador-geral de Justiça, os quais ficaram responsáveis pelo apoio e operacionalização do projeto.

Para consolidação do projeto de uma nova arquitetura organizacional foram identificadas as seguintes etapas:

I. Alinhamento conceitual: fundamentação teórica e definição do modelo organizacional. Nessa ocasião, os integrantes da comissão constituída por servidores do MPRN foram capacitados quanto aos pressupostos teóricos que permeariam o trabalho. Nesse estágio houve o aprofundamento de estudos relacionados à burocracia e modelos de estrutura organizacional voltados para o setor público.

II. Diagnóstico situacional: levantamento de informações sobre a atual estrutura das unidades administrativas, recursos humanos disponíveis, principais dificuldades encontradas para a consecução dos objetivos institucionais e coleta de sugestões para a otimização do desempenho dos setores realizada com os representantes da administração superior, órgãos auxiliares do Ministério Público Estadual e demais unidades administrativas.

III. Análise crítica: avaliação crítica das informações, por meio da classificação de cada uma das unidades de acordo com as atividades desempenhadas, destacando-se os problemas evidenciados e a estrutura proposta por unidade ministerial. Essa etapa consistiu em uma série de reuniões entre os integrantes da comissão, com a participação eventual de colaboradores, para deliberar sobre as soluções mais adequadas para a configuração da nova arquitetura organizacional.

IV. Minuta do organograma estrutural: proposição de um novo organograma, fruto das constatações observadas na fase anterior, obedecendo às seguintes diretrizes:

、 redistribuição de atividades concentradas em uma única unidade;

v formalização de unidades administrativas que atuam na informalidade;

v compatibilização da estrutura das unidades ministeriais às demandas administrativas;

v criação de estrutura de apoio administrativo e técnico-especializado aos órgãos da administração superior e órgãos auxiliares do Ministério Público Estadual;

\ criação de unidades para áreas estratégicas, atualmente não consignadas no organograma da Instituição;

v descentralização das atividades administrativas, com a interiorização da gestão;

v modernização da estrutura organizacional, por meio da redefinição das unidades com base nas normas de O\&M (Organização e Métodos);

v análise da real necessidade da criação da unidade funcional de acordo com as diretrizes para classificação das áreas organizacionais;

\ definição de requisitos para investiduras nos cargos, compatíveis com as atividades desempenhadas, de forma a profissionalizar os cargos gerenciais. 
O modelo de organograma deveria ainda obedecer à seguinte configuração:

$\checkmark$ unidades de staff da administração superior;

v unidades de apoio administrativo, em nível estratégico, tático e operacional;

จ estrutura de apoio aos órgãos de execução.

V. Definição da política remuneratória para os cargos de provimentos em comissão: para definição da política remuneratória, foi realizado um diagnóstico, conforme apresentado a seguir:

v inexistência de compatibilidade remuneratória associada às competências e complexidade dos cargos;

v falta de um padrão remuneratório;

v cargos políticos decisórios com remuneração incompatível com as atividades desempenhadas (administração superior);

$\checkmark$ falta de critérios para concessão de incentivos financeiros.

Feita essa análise, a equipe do projeto propôs soluções para cada um desses problemas, conforme adiante apresentado:

v estabelecimento de classes remuneratórias de acordo com o padrão de atividades desempenhadas, com a proposta de um padrão de $25 \%$ entre os cargos de acordo com o nível de atividade desempenhada (estratégico, tático ou operacional, assessoramento especial e técnico);

จ apresentação de um padrão remuneratório diferenciado para administração superior;

v criação de incentivos financeiros, vinculados às atividades desempenhadas e submetidos à avaliação periódica.

VI. Dimensionamento da força de trabalho para as unidades: a previsão de recursos humanos foi concebida levando-se em conta a necessidade de pessoal para operacionalização das atividades da nova arquitetura organizacional. Para tanto, foram analisados os seguintes pontos:

$\checkmark$ estrutura de recursos humanos atualmente disponíveis nas unidades;

v impactos das mudanças organizacionais previstas;

v análise das unidades funcionais e respectivas competências.

Após apresentação e a aprovação da proposta pela administração superior do MPRN, foram enviados projetos de Lei para a Assembleia Legislativa Estadual, os quais foram aprovados e posteriormente sancionados pelo Poder Executivo Estadual para a criação de novos cargos públicos necessários à implementação da nova estrutura organizacional.

\subsection{Implantação da nova estrutura organizacional}

O processo de implantação da nova estrutura organizacional durou aproximadamente um ano e foi realizado de forma gradativa, conforme informações obtidas na fase de análise docu- 
mental e entrevista, uma vez que foram observadas várias dificuldades no decurso do projeto, quais sejam:

v resistência à mudança e à adoção de novos procedimentos pelos gestores e integrantes das unidades administrativas;

v falta de pessoal e estrutura física deficiente nas unidades recém-criadas, tendo sido um processo moroso;

v dificuldade na transferência das competências de uma unidade para outra;

v ausência de um processo efetivo de comunicação e sensibilização entre os gestores.

Após a sanção das leis estaduais que consolidaram o processo de modernização administrativa, o MPRN iniciou um processo de implementação das mudanças propostas, por meio da adoção das seguintes medidas:

v provimento dos cargos de direção, chefia e assessoramento obedecendo à seguinte lógica procedimental: para os cargos que foram transformados, seus titulares foram nomeados para o novo cargo; as unidades informais foram providas pelos servidores que já executavam anteriormente as atividades das unidades criadas; e, por fim, os novos cargos foram preenchidos por meio de seleção pública;

v processo de formalização e transferência de competências entre as unidades novas e antigas, de forma que cada uma delas ficasse responsável integralmente por suas funções;

v elaboração do novo Regimento Interno;

- institucionalizado o novo organograma organizacional por meio de definição clara e precisa das competências de cada unidade.

Cumpre destacar que, após a conclusão do projeto, quando foram cumpridas as etapas elencadas no item anterior, o esforço da administração do MPRN foi no sentido de mitigar os focos de resistências, os quais permearam todo o processo de implantação, além de procurar garantir que unidades, gestores e servidores se apropriassem de suas competências e funções. Em consequência, foi realizado um processo contínuo de capacitação voltado para o desenvolvimento gerencial dos gestores, fortalecimento da comunicação e alinhamento entre as unidades.

Atualmente, todos os processos de trabalho já são executados por novas unidades, foi elaborado o manual organizacional, que formaliza as competências de cada unidade, e definida a política de gestão de processos na instituição, que vem sendo utilizada para mapeamento dos processos e atividades das unidades.

Ademais, passados aproximadamente três anos do projeto, está em andamento o processo de revisão da estrutura organizacional, cujo foco é readequar a estrutura às novas demandas e nova estratégia da organização e corrigir eventuais distorções observadas no processo de implementação da estrutura organizacional definida anteriormente. 


\section{Percurso metodológico}

O exame dos benefícios e impactos do processo de reestruturação da estrutura organizacional do MPRN, objeto deste artigo, consistiu das seguintes etapas:

a. recuperação dos relatórios, documentos, atas e demais registros do processo de avaliação com a ferramenta Gespublica;

b. recuperação dos relatórios e documentos de consultoria realizada com o objetivo de propor mudanças na estrutura organizacional;

c. elaboração de roteiro preliminar sobre os benefícios e impactos do processo de reestruturação da estrutura organizacional a partir dos relatórios e documentos de consultoria que expressavam uma expectativa de mudança organizacional com a adoção de nova estrutura organizacional;

d. contato com os integrantes da administração superior do MPRN para aplicação de questionário baseado no roteiro preliminar sobre benefícios e impactos com o objetivo de avaliar a nova estrutura proposta;

e. A avaliação dos desdobramentos administrativos decorrentes da implementação da nova estrutura foi feita com os integrantes da administração superior do Ministério Público, procurador-geral de Justiça, chefe de Gabinete e diretor-geral e diretores da Instituição nas áreas de Tecnologia da Informação, Finanças, Gestão de Pessoas e Corregedoria, com a aplicação de oito questionários. A escolha dos sujeitos se deu em função do envolvimento na definição e condução das políticas administrativas e pelo fato de que esses cargos são mais sensíveis às mudanças organizacionais.

\section{Avaliação do processo organizacional do MPRN}

O processo de implantação da nova estrutura organizacional está inserido em um contexto de mudanças exigidas ao MPRN e que passou pela necessidade de realinhar a estrutura organizacional. A aplicação do questionário permitiu conhecer várias dimensões desse processo, desde questões eminentemente operacionais até aspectos institucionais da atuação do Ministério Público.

Considerando que parte dos respondentes possuía uma visão técnica do processo de mudança, enquanto outra parte era constituída por integrantes do núcleo estratégico da Instituição, permitiu-se uma análise completa do processo de mudança organizacional e dos resultados esperados administrativos e finalísticos.

No que se refere ao processo de modernização administrativa relativamente à nova estrutura organizacional, verificou-se entre sete respondentes que a presença de unidades informais na estrutura organizacional foi a principal razão que levou à necessidade de reestruturação organizacional do MPRN; outros cinco respondentes citaram a defasagem do orga- 
nograma e a necessidade de descentralizar as atividades das unidades como causas principais que nortearam a construção da nova arquitetura organizacional do MPRN. Tais distorções organizacionais apontadas podiam levar à ineficiência administrativa e, por consequência, a falha no atendimento das demandas da população.

Observa-se, portanto, que a estrutura administrativa não era compatível à realidade da instituição, com a presença de unidades informais comprometendo o bom funcionamento da instituição e dificultando os fluxos de trabalhos e a definição de papéis e responsabilidades; por outro lado, a defasagem da estrutura implica dizer que o MPRN não possuía uma organização administrativa capaz de suportar as demandas internas e principalmente o atendimento das demandas da sociedade, na busca pelos serviços prestados pelos promotores e procuradores de Justiça. Nesse sentido, vê-se que esses dois pilares foram nevrálgicos para a decisão de se revisar a estrutura organizacional do MPRN.

No que tange à metodologia utilizada para construção da nova estrutura, cinco entrevistados avaliaram como bom, um avaliou como ótimo, outro avaliou como regular e um não soube responder, evidenciando, de maneira geral, a aprovação da metodologia de trabalho adotada. Esse entendimento é decorrente da avaliação de que as organizações públicas estão sujeitas a influências patrimonialistas em muitas de suas atividades. Assim, a condução técnica do trabalho, com apoio de consultoria especializada e com a formação de equipe especializada e por meio da adoção de ferramentas técnicas, afastou a possibilidade de interferências que alterassem o sentido da mudança que era desejada.

A condução de processos de mudança que alteram significativamente o funcionamento da Instituição e lidam com questões comportamentais exigiu a adoção de metodologias precisas capazes de enfrentar as resistências baseadas no rigor técnico do trabalho desenvolvido.

Destarte, o rigor metodológico e o embasamento técnico e científico que nortearam o trabalho tornaram-se fundamentais para consolidação do processo de construção da nova estrutura, uma vez que é comum em projetos dessa natureza realizados em organizações públicas que influências políticas ou pressões para favorecimento de determinadas unidades, estruturas ou pessoas, aconteçam.

Quanto aos impactos administrativos decorrentes da nova estrutura, há unanimidade entre os entrevistados no sentido de que a nova organização administrativa ajustou as demandas de trabalho existentes; outros quatro respondentes mencionaram o aumento da produtividade, a qual foi percebida pelos gestores na condução do trabalho nas respectivas unidades. Nesse contexto, reforça-se o entendimento de que a estrutura organizacional deve ser delineada de forma que a organização se torne capaz de atingir seus objetivos e estratégias organizacionais (Mintzberg, 2003). Insta destacar que os resultados alcançados, de acordo com os respondentes, atenderam às expectativas a que se propunha o projeto na busca por otimizar as atribuições, responsabilidades e competências de unidades administrativas, com, entretanto, apenas um dos entrevistados afirmando que a nova arquitetura organizacional não contribuiu para melhoria da Instituição.

Quando questionados sobre os fatores considerados positivos da nova arquitetura organizacional, todos os entrevistados citaram a distribuição das competências e três entrevistados 
mencionaram os critérios para provimento dos cargos e a metodologia utilizada no projeto. As fases de sensibilização, envolvimento de atores estratégicos e participação dos gestores, ou seja, o caráter participativo e a condução técnica das atividades foram fatores preponderantes para consecução do projeto, o que levou a minimizar as resistências naturais ao processo de mudança organizacional.

Outro ponto que mereceu destaque foram os critérios para provimento dos cargos de comissão por meio de critérios meritocráticos, através de processo seletivo amplo e público, permitindo a participação de qualquer cidadão que atenda aos critérios de provimento dos cargos, o que objetiva afastar as interferências patrimonialistas na nova estrutura; e, por fim, o rigor técnico do trabalho foi posto como condição essencial para consolidação do projeto, o que permitiu minimizar as resistências naturais decorrentes das mudanças organizacionais. Tais afirmações corroboram as informações obtidas anteriormente, que permitiram a realização de um trabalho técnico e desprovido de influências ou pressões internas.

Percebe-se que a nova estrutura vem ao encontro dos anseios administrativos no sentido de minimizar deficiências estruturais, assim como favorecer o melhor desempenho das atividades administrativas, evidenciado na afirmação de todos os entrevistados que afirmam que tal projeto foi de grande importância para o MPRN. De acordo com Herzog (1991), há três situações capazes de provocar ou catalisar uma mudança organizacional: crises ou problemas, novas oportunidades, e novas diretrizes internas e externas. No entanto, segundo Morgan (1996), a mudança é fruto de imagens e ideias que podem criar a cada momento novas ações.

Quando indagados sobre o que mudou com a implantação da nova arquitetura organizacional relativamente ao setor gerenciado de cada um dos entrevistados, mencionou-se a elevação da produtividade e agilidade do serviço, assim como uma maior descentralização das atividades internas, corroborando as informações apresentadas nos itens anteriores e confirmando os objetivos iniciais do projeto.

No que tange ao impacto da nova organização administrativa no desempenho das unidades, sete entrevistados afirmam que as atividades administrativas da unidade sob responsabilidade do gestor melhoraram; além disso, quando questionados acerca do que mudou na unidade, surgiram as seguintes respostas: aumentou a produtividade (sete), os serviços tornaram-se mais ágeis (cinco), descentralizaram-se as demandas (cinco), melhorou o fluxo do trabalho (dois), aumentou a demanda de trabalho.

Como se pode observar, de fato, houve uma repercussão positiva no desempenho institucional, pois os impactos apresentados repercutem diretamente no nível de eficiência e na melhoria do desempenho organizacional.

Para completar a análise, questionou-se aos respondentes quais pontos negativos observaram no processo de modernização administrativa do MPRN. A avaliação foi a seguinte: novas rotinas (dois), metodologia utilizada (dois) e comunicação deficiente (três). Verifica-se que dois dos pontos levantados dizem respeito ao processo de mudança, ou seja, as novas rotinas decorrentes das mudanças e a necessidade de comunicações eficientes para consolidação da nova estrutura organizacional. Tais afirmações reforçam a necessidade de se estabelecer um forte processo de sensibilização a fim de mitigar as resistências e fomentar um ambiente 
de mudanças e proatividade. No mesmo nível de importância foi o processo de comunicação eficiente de forma que todos os stakeholder estejam alinhados e cientes das etapas do trabalho, das ações em desenvolvimento, dos resultados esperados.

A avaliação do processo de mudança organizacional pelos integrantes da administração superior do MPRN permite afirmar que a mudança atingiu o sistema como um todo, que houve uma reconfiguração das relações de poder, que os serviços passaram a ser prestados em conformidade com as rotinas introduzidas, que foram criadas as condições iniciais para a consolidação de uma cultura de planejamento, que foram produzidos novos significados no âmbito interno da instituição e que as mudanças introduzidas estão gerando novos processos de mudança. Todos os resultados referenciados são coerentes com a proposição de Ferlie e colaboradores (1999), já discutida no texto, de que é a presença de um conjunto de indicadores que atesta de fato o processo de mudança.

\section{Conclusão}

O presente estudo teve o propósito de compreender o processo de construção da nova estrutura administrativa e sua repercussão no desempenho institucional do Ministério Público do estado do Rio Grande do Norte.

Observa-se que o processo de mudança iniciado no MPRN tem suas origens tanto externas quanto internas. A influência externa é decorrente do próprio processo de evolução da gestão pública que o Brasil vivencia, em busca da melhoria da eficiência das organizações públicas e da necessidade de atender satisfatoriamente à população que busca políticas públicas de qualidade.

Da perspectiva interna, percebe-se o aumento da demanda administrativa e a necessidade para fornecer o suporte técnico e operacional às Promotorias e Procuradoria de Justiça para o cumprimento de suas missões na defesa da sociedade.

Ademais, ficaram comprovados os reflexos positivos da nova estrutura organizacional no desempenho da Instituição, sobretudo na maior agilidade e produtividade no funcionamento das unidades administrativas, demonstrando que a estrutura alinhada à estratégia organizacional é condição sine qua non para a eficiência, a eficácia e a efetividade da Instituição.

De outro lado, faz-se necessário apresentar alguns aspectos que devem ser reforçados para assegurar a continuidade do processo de consolidação da nova estrutura do MPRN, que requer uma ação sistemática de monitoramento, melhorias e gerenciamento. A comunicação interna deve ser tratada com especial atenção a fim de se evitarem ruídos e falhas operacionais. Nessa mesma dimensão, o mapeamento e melhoria dos processos de trabalho, com o propósito de garantir a racionalidade administrativa e otimização do funcionamento da nova estrutura.

Ainda no sentido de aprimorar o funcionamento da estrutura do MPRN, o estabelecimento de indicadores de desempenho, assim como a revisão periódica da estrutura, a fim de avaliar sua aderência à estratégia da Instituição, deve ser uma preocupação presente de forma constante. 
Em termos de contribuições para a realização de novos estudos, sugere-se a realização futura de uma nova avaliação do impacto da implementação da estrutura organizacional levando-se em conta não apenas a percepção dos gestores de administração, mas também do público destinatário dos serviços ofertados pela nova estrutura organizacional, ampliando dessa forma o universo de análise dos impactos administrativos.

\section{Referências}

ABRUCIO, Luis Fernando; LOUREIRO, Maria Rita. Finanças públicas, democracia e accountability. In: ARVATE, Paulo Roberto; BIDERMAN, Ciro (Org.). Economia do setor público no Brasil. Rio de Janeiro: Elsevier; Campus, 2004. p. 78.

ANDRIOLO, Leonardo José. A Reforma do Estado de 1995 e o contexto brasileiro. In: ENCONTRO NACIONAL DOS PROGRAMAS DE PÓS-GRADUAÇÃO EM ADMINISTRAÇÃO — ENANPAD, 2006, Salvador. Disponível em: <www.anpad.org.br/enanpad/2006/dwn/enanpad2006-apsa-0480.pdf> . Acesso em: 31 maio 2015.

AUCOIN, Peter. Administrative reform in public management: paradigms, principles, paradoxes and pendulums. Governance, v. 3, n. 2, p. 115-137, abr. 1990.

BEHN, Robert D. O novo paradigma da gestão pública e a busca da accountability democrática. Revista do Serviço Público, v. 49, n. 4, p. 5-45, out./dez. 1998.

BESANKO, David; DRANOVE, David; SHANLEY, Mark. Economics of strategy. 2. ed. Nova York: Wiley, 1999.

BRASIL. Constituição da República Federativa do Brasil - 1988. Disponível em: <www.planalto. gov.br/ccivil_03/Constituicao/Constituiçao.htm>. Acesso em: 3 ago. 2013.

BRASIL. Presidência de República. Plano Diretor da Reforma do Aparelho do Estado. Brasília: Presidência da República, 1995.

BRESSER-PEREIRA, Luiz Carlos. Da administração pública burocrática à gerencial. Revista do Serviço Público, v. 47, n. 1, p. 7-29, jan./abr. 1996.

BRESSER-PERREIRA, Luiz Carlos. Do Estado patrimonial ao gerencial. In: PINHEIRO, Paulo Sérgio; WILHEIM, Jorge; SACHS, Ignacy (Org.). Brasil: um século de transformações. São Paulo: Companhia das Letras, 2001. Disponível em: <www.bresserpereira.org.br/papers/2000/00-73estadopatrimonial-gerencial.pdf $>$. Acesso em: 26 fev. 2015.

BRESSER-PEREIRA, Luiz Carlos. Uma reforma gerencial da administração pública no Brasil. Revista do Serviço Público, v. 49, n. 1, p. 5-42, jan./mar. 1998. Disponível em: <www.bresserpereira.org. br/papers/1997/97.Reforma_gerencial-RSP.pdf>. Acesso em: 31 maio 2015.

CHANDLER JUNIOR, Alfred D. Strategy and structure: chapters in the history of the American industrial enterprise. 20. ed. Massachusetts: MIT Press, 1998. 
CURY, Antonio. Organização \& métodos: uma visão holística. São Paulo: Atlas, 2006.

DRUCKER, Peter F. Prática de administração de empresas. Rio de Janeiro: Fundo de Cultura, 1962.

DUSSAULT, Gilles. A gestão dos serviços públicos de saúde: características e exigências. Rev. Adm. Pública, Rio de Janeiro, v. 26, n. 2, p. 8-19, abr./jun. 1992.

FERLIE, Ewan et al. A nova administração pública em ação. Brasília: Editora Universidade de Brasília; Enap, 1999.

HARMON, Michael M.; MAYER, Richard T. Teoría de la organización para la administración pública. México: Fondo de Cultura Económica, 1999.

HERZOG, J. P. People: the critical factor in managing change. Journal of Systems Management, Cleveland, v. 42, n. 3, p. 6-11, 1991.

HOOD, Christopher. The "new public management" in the 1980s: variations on a theme. Accounting, Organizations and Society, v. 20, n. 2/3, p. 93-109, 1995.

JUNQUEIRA, Luciano A. P. A mudança organizacional no setor público de saúde: delineamento de uma metodologia. Rev. Adm. Pública, Rio de Janeiro, v. 26, n. 2, p. 139-144, abr./jun. 1992.

KISSIL, Marcos; PUPO, Tânia R. G. B. Gestão da mudança organizacional. São Paulo: Faculdade de Saúde Pública da Universidade de São Paulo, 1998. Disponível em: <www.saude.mt.gov.br/ arquivo/2951>. Acesso em: 1ํjun. 2015.

KLIKSBERG, Bernardo. Como transformar o Estado: para além de mitos e dogmas. Brasília: Enap, 1992.

KOOIMAN, Jan. Modern governance: new government-society interactions. Califórnia: Sage, 1993. MATUS, Carlos. Estrategia y plan. 10. ed. Buenos Aires: Siglo Veintiuno, 1993.

MINISTÉRIO PÚBLICO DO ESTADO DO RIO GRANDE DO NORTE. Mapa das comarcas do MPRN. Disponível em: <www.mprn.mp.gov.br>. Acesso em: 15 ago. 2013.

MINTZBERG, Henry. Criando organizações eficazes: estruturas em cinco configurações. 2. ed. São Paulo: Atlas, 2003.

MISOCZKY, Maria C.; VIEIRA, Marcelo M. F.; LEÃO, Fernando P. S. Dimensão política e dimensão técnica das definições de qualidade no serviço público municipal: o caso da Prefeitura Municipal do Recife. In: ENCONTRO DA ASSOCIAÇÃO NACIONAL DOS PROGRAMAS DE PÓS-GRADUAÇÃO EM ADMINISTRAÇÃO, 23., 1999, Foz do Iguaçu. Anais... Rio de Janeiro: Anpad, 1999. 1 CD-ROM.

MORGAN, Gareth. Imagens da organização. São Paulo: Atlas, 1996.

NUNES, Edson. A gramática política do Brasil: clientelismo e insulamento burocrático. 3. ed. Rio de Janeiro: Jorge Zahar; Brasília: Enap, 1997.

OLIVEIRA, Djalma P. R. Sistemas, organização \& métodos: uma abordagem gerencial. 13. ed. São Paulo: Atlas, 2002. 
PALVARINI, Bruno C. O que é gespública. 2010. Disponível em: <www.gespublica.gov.br/folder_ rngp/anexos/saiba_mais_gespublica.pdf>. Acesso em: 28 fev. 2015.

PEARCE II, John A.; ROBINSON JUNIOR, Richard B. Strategic management: formulation, implemention and control. 7. ed. Nova York: McGraw-Hill, 2000.

PETTIGREW, Andrew M. Context and action in the transformation of the firm. Journal of Management Studies, v. 24, n. 6, p. 649-670, nov. 1987.

POLLITT, Christopher; BOUCKAERT, Geert. Avaliando reformas da gestão pública: uma perspectiva internacional. Revista do Serviço Público, v. 53, n. 3, p. 5-30, jul./set. 2002.

RHODES, Roderick A. W. Understanding governance: policy networks, governance, reflexivity, and accountability. Philadelphia: Open University Press, 1997.

RUA, Maria G. Desafios da administração pública brasileira: governança, autonomia, neutralidade. Revista do Serviço Público, v. 48, n. 3, p. 133-152, set./dez. 1997.

SADEK, Maria Tereza et al. Uma introdução ao estudo da Justiça. Rio de Janeiro: Centro Edelstein de Pesquisas Sociais, 2010.

SEIFFERT, Peter Q.; COSTA, João A. S. Estruturação organizacional: planejando e implantando uma nova estrutura. São Paulo: Atlas, 2007.

SOUZA, Wertson B. Interesse público e resistência à mudança: estudo de casos em uma Secretaria de Estado. 1994. Dissertação (mestrado em administração) — Centro de Pós-graduação e Pesquisas em Administração, Faculdade de Ciências Econômicas, Universidade Federal de Minas Gerais, Belo Horizonte, 1994.

SUBIRATS, Joan; QUINTANA, Imma. Hacia la segunda descentralización en España ¿̇son los municipios parte de la solución? los claroscuros de la descentralización local. Instituto de Gobierno y Políticas Públicas. Barcelona: Universidad Autónoma de Barcelona, 2005.

VASCONCELLOS, Eduardo; HEMSLEY, James R. Estrutura das organizações: estruturas tradicionais, estruturas para a inovação, estrutura matricial. São Paulo: Pioneira Thomson Learning, 2003.

XAVIER, Raquel O.; DIAS, Sônia Maria R. C. Avaliando a mudança: a percepção dos gerentes sobre o comportamento organizacional após a privatização. In: ENCONTRO NACIONAL DOS PROGRAMAS DE PÓS-GRADUAÇÃO EM ADMINISTRAÇÃO — ENANPAD, 26., 2002, Salvador. Anais... Rio de Janeiro: Anpad, 2002. 1 CD-ROM.

Jean Marcel Cunto Lima é mestre em administração pela Universidade Federal do Rio Grande do Norte (UFRN).E-mail: jeanmclima@gmail.com.

Juliana Perez Ruggiro Jacobini é mestre em administração pela Universidade Federal do Rio Grande do Norte (UFRN). E-mail: jujacobini@yahoo.com.br.

Maria Arlete Duarte de Araújo é professora titular do Programa de Pós-Graduação em Administração da Universidade Federal do Rio Grande do Norte (UFRN). E-mail: mariaarlete1956@gmail.com. 